\title{
O CURRÍCULO, A EDUCAÇÃO MUSICAL E AS REALIDADES INDIVIDUAIS DE CADA ESTUDANTE: UM ENSAIO EM DEFESA DA INCLUSÃO CULTURAL NO ENSINO DE MÚSICA
}

\author{
The curriculum, music education and the students' \\ individual realities: an essay in defence of cultural \\ inclusion in music teaching
}

\author{
JOÃO GOMES REIS \\ Escola Superior de Educação - Politécnico do Porto/Portugal \\ joao.gomesreis@hotmail.com \\ PEDRo DuARTE \\ Escola Superior de Educação - Politécnico do Porto/Portugal \\ pedropereira@ese.ipp.pt
}

\begin{abstract}
Resumo: $O$ presente texto ${ }^{1}$ tem como principal objetivo discutir a necessidade de se valorizar os vários géneros musicais, nomeadamente aqueles que se encontram culturalmente mais próximos dos alunos, e promover diferentes práticas pedagógico-curriculares associadas a esta dimensão, potenciando uma educação musical mais inclusiva, ativa e completa. Para isso, o ensaio está divido em duas secções distintas. Na primeira secção, refletimos sobre o ensino formal, integrando três dimensões distintas: o currículo; a ideologia e a cultura; o estudante enquanto indivíduo. Na segunda secção, discutimos conceitos relacionados à educação musical, problematizando-se, com maior enfâse, questões relacionadas com a hegemonia curricular, pedagógica e cultural associada ao ensino da música. Com este texto, procuramos trazer para o debate educativo o reconhecimento da individualidade de cada estudante no contexto escolar e, em particular, na educação musical. Defendemos, assim, um currículo, no âmbito do ensino da música, que seja consciente da dimensão cultural dos processos educativos e que potencie um repertório em que evidencia e valoriza a multiculturalidade associada às sociedades contemporáneas.
\end{abstract}

Palavras-chave: Currículo. Educação musical. Cultura(s).

\begin{abstract}
The following text aims to discuss the necessity of valuing the variety of music genres, namely those that are culturally closer to students, and to promote different pedagogical and curricular practices associated with this issue, promoting a more inclusive, active and complete music education. To achieve this, the present essay is divided in two distinct sections. In the first section, we reflect about formal education, integrating three distinct dimensions: the curriculum, ideology and culture, and the student as an individual. In the second section, we discuss concepts related to music education, focusing in greater detail on issues about curricular, pedagogical, and cultural hegemony. With this text we are trying to bring up to the educational debate the validation and recognition of every students' individuality in the school context, especially in music education. Therefore, we advocate a music education curriculum that is aware of the cultural dimension of the educative processes and allows a kind or repertoire that values the multiculturality associated with contemporary societies.
\end{abstract}

Keywords: Curriculum. Music education. Culture(s).

${ }^{1} \mathrm{O}$ texto encontra-se escrito em Português europeu. 


\section{INTRODUÇÃO}

Vivemos num mundo marcado pela sua cultura plural. Ainda assim, não é necessário sairmos do âmbito do nosso país para observarmos inúmeros contextos e experiências culturais e étnicas distintas. A democratização do ensino e a abertura da escola a toda a população foi um passo dado no sentido do fim da segregação e exclusão de crianças e jovens, reconhecendo, assim, o seu direito à educação (Stoer, 2001) No entanto, este processo enfrenta diferentes desafios, nomeadamente a dificil adaptação de muitos alunos à cultura escolar, que até então lhes era desconhecida e que não considera a sua herança cultural ou as vivências individuais como conhecimento válido. Tal como é alertado por Silva (2010), os contextos sociais, entre eles o contexto escolar, convivem, paradoxalmente, com a diversidade e com a homogeneização cultural.

É possivel reconhecer que o ensino formal de música apresenta, por vezes, dinâmicas semelhantes. Em Portugal, por exemplo, este ensino foi, em parte, influenciado por uma educação originária do modelo do Conservatório de Paris e está fortemente marcado pela tradição musical da Europa Ocidental, recusando-se a incluir qualquer outro tipo de repertório. A este propósito, recordam-se as palavras de Rosa, que indica que no século XIX, durante um periodo de transição normativa, foi determinado

que se seguissem os [compêndios e obras elementares para as aulas] do Conservatório de Paris "e as obras dos auctores classicos", evidenciando-se desde logo a referência ao modelo francês, matriz fundamental de todos os Conservatórios europeus oitocentistas (2000, p. 92).

Face ao exposto, em linha com o que acontece no ensino geral, muitos dos estudantes têm dificuldade em se identificarem com esta cultura musical, tão distante da deles.

Neste ensaio, reflectiremos sobre os desafios com maior relevância na escola de hoje e concretizaremos uma caracterização do ensino formal de música e da sua tradição centenária, com o fim de estabelecer um paralelismo entre estes dois mundos não assim tão distantes. De seguida, abordaremos a temática da inclusão das músicas populares - a música culturalmente mais próxima das crianças e jovens deste século - no currículo do ensino formal de música, bem como uma adaptação das práticas aliadas a estes idiomas musicais em prol de uma educação musical mais ativa, criativa e completa. E, neste sentido, torna-se relevante lembrar o que já havia dito McPhail (2014) sobre a perpetuação do binómio: música escolar vs. música não escolar. 


\section{O ENSINO: AS DINÂMICAS ENTRE INDIVÍDUO, CULTURA E CURRÍCULO}

Antes de abordarmos a temática do repertório considerado no ensino formal de música, assume-se como significativo concretizarmos uma breve reflexão sobre o sistema educativo e a educação, pois muitas das questões que se colocam em relação ao estado da Educação Musical são homólogas ou, pelo menos, bastante semelhantes às que se irão expor a seguir.

Por força da globalização do saber, da comunicação e da consequente aproximação das nações e dos povos, ocorreu um súbito desenvolvimento do multiculturalismo. Enquanto não existiu esta aproximação cultural, parafraseando Stoer (2001, p. 185), "ser-se etnocêntrico era uma posição relativamente pacífica". No presente, porém, somos obrigados a pensar a unidade humana na base da sua diversidade cultural (Archer, 1991).

Como refere Leite (2005), as sociedades europeias - e, por inerência, as organizações educativas - foram-se tornando cada vez mais multiculturais por força de vários acontecimentos, resultando, hoje, num projeto comum, plural, diverso e com um nível de aceitação alto em relação a essa diversidade cultural.

De facto, esta nova perspetiva face à sociedade influiu sobre vários quadrantes da mesma, incluindo a educação. A abertura da escola a todos e a massificação do ensino trouxeram para dentro do contexto escolar um leque vasto de identidades culturais distintas.

Ainda assim, a ideologia de democratização da sociedade portuguesa, e do acesso ao ensino, ao não ser devidamente acompanhada pelas necessárias reformas curriculares e estruturais, tem provocado a exclusão daqueles que não se enquadram na cultura escolar (Leite, 2005). Os valores e as perspetivas sociais e culturais dos alunos, fruto das experiências vividas nos seus contextos quotidianos que, desde então, aconteciam de forma paralela àquela cultura, não se enquadraram na forte categorização e classificação $o^{2}$ dos saberes da escola. Patacho (2011, p. 45) aborda esta questão muito explicitamente:

Estas crianças e jovens veem-se na dura realidade de terem de escolher entre a sua identidade cultural e a subordinação aos padrões culturais veiculados como superiores, que devem tentar, com esforço, adquirir.

Patacho (2011), acerca da escola em Portugal, alerta para a existência de uma supremacia cultural que ocasiona um dilema de identidade cultural em muitos estudantes. Além disto, afirma que esta é regulada por padrões

\footnotetext{
2 Segundo Basil Bernstein (1971), a classificação refere-se ao grau de preservação das fronteiras entre categorias. O grau de classificação é forte quando existem claras separações ou fronteiras entre categorias, originando uma hierarquia onde cada uma tem um estatuto e, consequentemente, um poder determinado.
} 
eurocêntricos, brancos, burgueses e heterossexuais. Sobre este assunto, Torres Santomé (2004, p. 10) acrescenta uma descrição similar:

Nas análises de matérias curriculares que faço periodicamente, as escolas continuam a pensar que no mundo só existem homens de raça branca, de idade adulta, que vivem em cidades, empregadas, cristãos, de classe média, heterossexuais, elegantes, saudáveis e robustos (p. $10)$.

De modo complementar, Patacho (2011) perspetiva que, na dinâmica do discurso, a escola continua a estruturar-se em torno de valores como a emancipação e a liberdade, porém são reconheciveis lógicas de atuação que tendem a subordinar esses ideais às necessidades da economia e do mercado de trabalho. Neste sentido, "os alunos na escolaridade obrigatória não refletem sobre as relações de poder existentes nas sociedades" (Torres Santomé, 2004, p. 10) ao serem omitidas do currículo questões relacionadas à pobreza e suas causas, às etnias oprimidas e as suas condições de vida ou às consequências da centralização dos recursos nos grandes centros urbanos. Mas uma escola comprometida com a justiça social e a liberdade tem de incluir estes temas como conteúdos dos programas para os estudantes (Moreira, 1996; Silva, 2010; Torres Santomé, 2004).

Se os problemas relativos ao acesso ao ensino foram, em grande parte, colmatados pela democratização da educação, o problema do sucesso daqueles que não se enquadram nos padrões hegemónicos da sociedade e da escola, por sua vez, é um produto deste mesmo processo. Tal problema é apresentado como insucesso escolar, um conceito regularmente ouvido no contexto escolar, não sendo por norma considerados os aspetos de âmbito sociocultural que o envolvem (Silva, 2010). Ao mesmo tempo, os alunos que realmente têm sucesso são aqueles que se encontram alinhados com os padrões culturais veiculados pela escola ou aqueles que conseguem adaptar-se, absorvendo os novos valores que vão substituindo os seus (Torres Santomé, 2004).

Recuperando a perspetiva de Apple e Aasen (2003), é necessário reconhecer, ainda, as diferentes pressões políticas e sociais que influenciam as escolas, pelo que é imprescindivel não menosprezar essa realidade politica assente na intenção de se institucionalizarem particulares culturas nos contextos educativos. Esta perspetiva, como as dos vários autores referidos até o momento, coloca a tónica em questões e problemáticas associadas às teorias pós-críticas do currículo e que integram as dimensões relacionadas com o multiculturalismo e com a sexualidade, por exemplo. Não desvalorizando os contributos das teorias críticas do currículo, que evidenciaram a relevância da reprodução cultural e social, da ideologia e da emancipação nos estudos curriculares, as teorias pós-críticas acentuam a dimensão cultural e subjetiva das dinâmicas curriculares (Silva, 2010). 
Ter em consideração a multiculturalidade da sociedade, no âmbito da educação, implica considerar, valorizar e desafiar as identidades plurais das/nas práticas curriculares e pensar sobre - e combater - os "mecanismos discriminatórios ou silenciadores da pluralidade cultural" que "buscam homogeneizá-la em conformidade com uma perspetiva monocultural" (Moreira, 2000, p. 3). Existe, portanto, um potencial choque entre as culturas dos alunos e a cultura escolar e uma realidade que simplesmente não é abordada e discutida no âmbito da escola.

Patacho (2011) afirma que a escolas e o currículo têm de ser construídos a partir de baixo, ou seja, a partir das culturas e vivências dos alunos, das suas famílias e comunidade, e que está nas mãos dos professores criar as condições de diálogo e cooperação que resultem em projetos educativos desta natureza. Assumindo-se, portanto, uma abordagem socioconstrutivista que privilegia uma dimensão individual dos estudantes, integrando no currículo a dimensão pessoal e relacional dos alunos e conferindo relevo à sua herança cultural (Henley, 2018).

Finalizando, e ainda em linha com este pensamento, Dewey (2007) enfatiza a necessidade de a escola ser uma expansão livre das experiências vividas pelas crianças e pelos jovens através da edificação de condições para que os estudantes participem ativamente na construção do meio e da cultura, o que se traduz na habilidade de cada um ser constantemente capaz de ampliar a sua cultura.

\section{O ENSINO DE MÚSICA: TENSÕES ENTRE TRADIÇÃO, IDENTIDADE E DIVERSIDADE CULTURAL/MUSICAL}

Após a anterior, e breve, análise da realidade escolar, é nossa intenção, nas próximas linhas, fazer uma transposição de algumas das ideias abordadas e enquadrá-las no ensino formal de música, onde um certo pensamento hegemónico não é tão diferente assim, e talvez até seja mais óbvio e facilmente assinalável.

O ensino formal de música, na maior parte do mundo, centra-se quase exclusivamente na tradição musical da Europa Ocidental, comummente chamada de "música clássica" ou "erudita". Isto deve-se a um ciclo contínuo de reprodução e da cristalização do modelo de ensino característico do Conservatório de Paris.

Aquando da sua criação, o Conservatório de Paris mudou muitos dos valores musicais tidos até então. Um dos ideais mais marcantes deste modelo - de que o instrumentista deveria funcionar apenas como um meio de transmissão das obras musicais dos compositores - veio alterar significativamente as práticas pedagógicas e, principalmente, a forma como a música passaria a ser encarada e pensada. Assim, a arte musical deixou de ser algo que outrora funcionara como acompanhamento de ocasiões ou eventos, com um carácter efémero, transformando-se num objeto a ser 
reproduzido, o mais concordante possivel com a vontade do compositor (a partitura), com valor exclusivamente em si mesmo e alienando, entre outros fatores, os públicos (Sloboda; Ford, 2012).

Esta nova visão era encorajada pelo Conservatório de Paris, através da ênfase dada à especialização num só instrumento e numa procura de uma técnica virtuosística para que fosse possivel uma precisa reprodução da partitura do compositor e uma performance musical standard. Um dos métodos de normalização do ensino de música foi, por exemplo, a obrigatoriedade da publicação dos métodos e manuais de estudo, por parte dos professores. Isto resultou numa homogeneização do ensino e das práticas pedagógicas, com a criação de standards oficiais, monitorizados através de exames e competições (concursos), afastando-se a prática educativa que se centrava nas características, nos conhecimentos e nas idiossincrasias dos professores. Esta pedagogia "clássica" parece ser o produto de valores como a disciplina, em vez da expressão; o intelectualismo, em vez do sentimento ou vontade, e a apatia, em vez da paixão (Hein, 2016).

Devido a esta mudança de paradigma, os conservatórios passaram a ser encarados como os guardiões e protetores de um certo cânone musical, com ideias acerca do repertório, da técnica e da interpretação muito bemdefinidas, com a intenção de transformar os seus alunos em executantes e representantes desta cultura musical definida pela sua (fictícia) universalidade e pela sua transcendência além do popular, efémero, étnico e mundano (Sloboda; Ford, 2012; Hein, 2016).

Podemos constatar, então, que a praxis nas instituições de ensino formal de música converge num único sentido estético e é dominada pela música da tradição da Europa Ocidental (Costa; Pinto; Pais-Vieira, 2017) ${ }^{3}$, que desvaloriza as práticas mais informais e de conhecimento procedimental em detrimento da valorização da dimensão formal e conceptual do conhecimento musical (McPhail, 2014).

A cultura de muitos dos alunos pode, porventura, entrar em conflito com a cultura das instituições de ensino formal de música por limitar o repertório utilizado quase exclusivamente a estruturas e formas musicais dos séculos XVIII e XIX (Costa; Pinto; Pais-Vieira, 2017; Monteiro, 2001). A estagnação é óbvia, visto que nos encontramos já no século XXI.

Butler, Lind e McKoy (2007) dizem-nos que a música tem significados construídos socialmente e que reside, também nela, a origem da identidade cultural de vários grupos. Sublinham, ainda, que o desenvolvimento da identidade é um aspeto importante na educação, e que este é mediado pelo

\footnotetext{
${ }^{3}$ No artigo citado, os autores referem-se ao repertório utilizado na disciplina de Formação Musical. No entanto, esta disciplina é apenas uma de todo um currículo dominado pelo mesmo tipo de repertório, tendose tomado a liberdade de utilizar a formulação escrita pelos mesmos e generalizado esta ideia para o ensino de música na sua totalidade.
} 
contexto racial, cultural e social, estando inclusivamente relacionado com conceitos como autoestima, autoconceito e influência de grupo. De facto, segundo Hargreaves, MacDonald e Miell (2002), a música pode ser utilizada como forma de formularmos as nossas identidades individuais e de nos expressarmos e apresentarmos perante os outros. Os padrões pessoais de preferência, descritos muitas vezes como "gosto musical", podem ser uma parte importante do autoconceito dos indivíduos e, em muitos casos, criar uma representação importante dos seus valores e atitudes, o que é especialmente observável na adolescência.

O conceito de identidades musicais, segundo aqueles mesmos autores, divide-se em duas partes: identidades na música e música nas identidades. As identidades na música lidam com os aspetos socialmente definidos por papéis culturais e categorias dentro do campo da música e com o modo como as pessoas se relacionam com eles. Por exemplo, como se posicionam dentro dos padrões das carreiras profissionais dos músicos (se são compositores, músicos, professores, críticos etc.) e os motivos pelos quais um indivíduo se identifica com um género ou estilo musical em particular, sendo neste caso uma identidade de grupo (no papel de público ou músico). A música nas identidades refere-se às formas como a música poderá ser usada como recurso na formação da identidade pessoal e como parte integrante de outros aspetos do autoconceito do indivíduo, como idade, género ou identidade nacional. O dominio da música poderá variar consideravelmente consoante o treino musical e o grau de interesse específico. A título de exemplo, profissionais na área da música poderão estar tão envolvidos nas suas práticas no domínio da música que verão a maior parte das outras dimensões da vida em relação à música, colocando aquelas atividades específicas no centro da sua identidade (Hargreaves; Marshal, 2003).

Por outras palavras, as pessoas constroem ativamente as suas identidades musicais, seja no papel de público, apreciadores ou músicos, e tal pode ser determinante no desenvolvimento de competências, da confiança, da identidade e no alcance de certos objetivos.

A este respeito, torna-se relevante refletir sobre a exclusão da maior parte das músicas do currículo do ensino formal de música, o que origina uma quantidade significativa de contextos e experiências culturais e musicais que não vão ser, em nenhuma instância, reconhecidos ou abordados. Em concordância com o descrito, Green (2006) diz-nos que:

Muitos estudantes têm experiências ambiguas, ou pior, experiências alienadas de uma variedade musical resultante 
de uma relação negativa com a música presente na sala de aula (p. 106, tradução nossa) ${ }^{4}$.

No seguimento desta ideia, acrescenta que os estudantes que são ensinados com a música da tradição europeia ocidental, através do canto e da audição da mesma, são forçados a estudar uma música na qual não encontram nenhum ponto de identificação ou contacto.

No ensino formal de música, o poder de decisão sobre quais os idiomas ou géneros musicais a serem utilizados e abordados recai, habitualmente, sobre os professores. Muitas vezes, o exercício deste poder, de definir o que conta como música, tem sido executado a par de uma exclusão de idiomas classificados negativamente pela tradição clássica por serem entendidos como música subdesenvolvida, primitiva e não séria (Swanwick, 1988, 1991).

Uma das principais características identificadas por Hargreaves e Marshal (2003) nos professores de música ${ }^{5}$, que pode contribuir para a manutenção dos métodos clássicos, é o facto da quase totalidade destes terem uma formação académica clássica ou tradicional e que se baseia na tradição dos conservatórios, assumindo, por isso, um perfil académico muito específico. Parece-nos sensato afirmar que é definitivamente problemática a noção de que um excelente músico deve ser fluente noutros idiomas musicais, saindo da sua zona de conforto. Igualmente complexa é a mesma questão, mas em relação aos docentes da área da música, também eles músicos, pretendendo-se que dominem outros idiomas, com o intuito de os abordarem pedagogicamente, que não pertencem à sua área de formação. É de ressalvar, todavia, que os professores trazem uma variedade de experiências pessoais para o contexto da sala de aula e entendê-las e relacioná-las entre si é do interesse dos educadores para maximizar as aprendizagens significativas dos alunos.

Um dos objetivos principais da educação musical é o desenvolvimento da apreciação de vários estilos e géneros musicais, por parte dos estudantes, bem como a fomentação de uma atitude crítica em relação à música que permita uma avaliação da mesma que considere uma multiplicidade de critérios (Green, 2006; Butler; Lind; McKoy, 2007; Swanwick, 1988, 1991). As instituições de ensino devem ser, portanto, locais onde os alunos conhecem e experimentam as realidades musicais existentes, e um dos papéis do professor é o de familiarizar os seus estudantes com as convenções estruturais das mesmas, através de uma participação ativa no seu processo formativo (Green, 2006).

\footnotetext{
4 "Many pupils have ambiguous experiences, or worse, alienated experiences of a variety of music resulting from negativity towards [...] much of classroom music".

${ }^{5}$ Tal estudo diz respeito apenas à Grã-Bretanha, no entanto, podemos considerar que o tipo de ensino formal de música na Europa é transversal às diferentes realidades nacionais.
} 
As etiquetas ${ }^{6}$ que são atribuídas a alguns tipos de música, de certa forma, filtram e moldam as atitudes e julgamentos de valor em relação aos mesmos. Se a decisão do repertório for feita partindo de uma posição inflexivel acerca dos idiomas fora do âmbito da tradição clássica, não será possível sequer considerar qualquer outro tipo de objeto musical sem que automaticamente se efetue este processo de etiquetagem e de exclusão (Swanwick, 1988). Os decisores têm de partir de uma posição neutra para que se faça uma seleção pensada, adequada e que considere as vantagens e desvantagens da utilização de outro tipo de repertório.

\section{UM REPERTÓRIO CULTURALMENTE PRÓXIMO DOS ALUNOS}

A cultura musical dominante fora do âmbito académico traduz-se nas várias músicas populares. O termo popular music é muito abrangente, incluindo uma variedade de contextos socioculturais e práticas diferenciadas, sendo muitas vezes dominado por perspetivas económicas e de mercado ("aquilo que vende", "aquilo que apela aos públicos" etc.). Mas o habitus $^{7}$ que o rege é transversal a vários estilos, géneros ou idiomas musicais, como jazz, rock, pop, dance, metal e muitos outros (Middleton; Manuel, 2001).

A preferência pela música popular atual por parte das crianças e jovens já foi estudada e publicada por vários autores (Greer; Dorow; Randall, 1974; Shehan, 1984; Hargreaves; North, 2009). Num estudo sobre a educação musical no ensino secundário, para o qual se inquiriram alunos sobre os seus hábitos de audição de música, na Grã-Bretanha, Hargreaves e Marshal (2003) conferiram que a maior parte da música ouvida regularmente pelos alunos se situava no âmbito da música popular e que apenas $10 \%$ dos inquiridos ouviam música clássica ou jazz ${ }^{8}$. Com efeito, a música popular não só ocupa um papel central na vida de muitos jovens indivíduos, como é frequentemente usada como representação da sua identidade. No entanto, nenhum destes estilos de música é ensinado ou sequer considerado no currículo da grande maioria das instituições de ensino formal de música.

Sobre o presente assunto, torna-se pertinente recordar que o currículo pode ser pensado de várias formas. Tradicionalmente, é conceptualizado como o conhecimento tratado pedagógica e didaticamente pela escola e a ser aprendido pelos estudantes. Noutras abordagens, associadas às teorias críticas e pós-críticas (Silva, 2010), o currículo significa o conjunto de experiências a serem vividas pelo estudante sob a orientação da escola (Moreira, 1996). Só de acordo com a segunda conceção é possivel uma abertura do repertório, tendo em consideração os alunos, afastando-se a

\footnotetext{
6 Tradução literal do conceito de label, utilizado por Keith Swanwick (1991). A derivação labelling também surge mais à frente, traduzida como "etiquetagem".

${ }^{7}$ Sobre este conceito, conferir Bourdieu (1977).

${ }^{8}$ Os autores do estudo juntaram a música clássica e o jazz na mesma categoria.
} 
hegemonia existente que fecha e condiciona as experiências musicais dentro das instituições. Mais, permite uma representação da realidade vivida pelos indivíduos fora das academias e conservatórios de música dentro dos mesmos, validando todo um leque de conhecimentos e saberes que ainda tendem a ser desvalorizados. A este respeito, McPhail (2014) sugere que

Os estudantes parecem mais envolvidos quando os professores conseguem gerir a relação entre as várias formas de conhecimento: gerir o equilíbrio entre as exigências epistémicas e sociais da conceção e realização do currículo. No geral, parece existir um alinhamento entre o conhecimento e as experiências que os estudantes consideram importantes e significativas: um alinhamento entre aquilo que eles esperam que a música na escola promova e os objetivos e ações dos seus professores (p. 323, tradução nossa) ${ }^{9}$.

Em sintonia com o mencionado, a introdução de outros tipos de música, nomeadamente a música mais próxima da cultura e das vivências dos alunos, será certamente positivo e motivante para os mesmos. Contudo, deve haver a preocupação em não centrar a discussão somente no repertório, pois este não pode ser considerado, em nenhuma instância, independentemente dos contextos onde o encontramos ou das práticas que lhe estão associadas. Se focarmos num tipo de repertório em detrimento de outro, estamos a criar uma hierarquia entre músicas e entre práticas musicais, tornando a discussão contraproducente (Henley, 2018). Não chega só mudar as peças musicais abordadas, sendo também essencial alterar, em contexto escolar, os processos através dos quais aquelas são introduzidas e trabalhadas. Então, emerge como necessário observar quais são as diferenças fundamentais entre as práticas formais do ensino formal de música (clássico) e as práticas informais características da música popular.

Segundo a comparação elaborada por Lucy Green (2006), entre os processos de aprendizagem musical informais e formais:

(1) os alunos escolhem a música que querem trabalhar, com a qual estão familiarizados e se identificam. Em contraste, no ensino formal clássico, são os professores que escolhem a música, com a intenção de apresentar aos alunos áreas não familiares;

(2) a principal prática informal de aprendizagem é a cópia ou memorização auditiva das músicas, distinguindo-se de uma prática assente na leitura de notação musical;

\footnotetext{
9 "Students seemed most fully engaged where teachers were able to manage the relationship between various forms of knowledge: managing to balance both the epistemic and social demands of curriculum conception and realisation. Overall it seemed that there was an alignment between the knowledge and experiences students regard as important and powerful: an alignment between what they hope and expect subject music will provide for them and the aims and actions of their teachers" (p. 323).
} 
(3) o aluno é autodidata e, mais importante ainda, a aprendizagem acontece em grupos. Isto pode ocorrer consciente ou inconscientemente, através da interação com os pares e fruto de discussão, observação, audição ou imitação. No domínio formal, normalmente está sempre envolvido um adulto com conhecimento e competências superiores que supervisiona e guia a ação;

(4) uma aprendizagem musical informal envolve o desenvolvimento de competências e conhecimentos, de forma pessoal e individualizada, por vezes incidental, relacionada com as preferências musicais do aluno e partindo de músicas "reais". No ensino formal de música, os alunos seguem uma progressão do simples para o complexo, que muitas vezes envolve um repertório especialmente composto para fins educativos;

(5) ao longo do processo há uma relação estabelecida entre audição, interpretação, improvisação e composição, com ênfase na criatividade e expressão pessoal, ao contrário do que acontece nos modelos reproduzidos pelas instituições de ensino formal de música, onde existe uma separação das competências, com incidência na reprodução, como já foi exposto neste trabalho. Existem, portanto, processos de aprendizagem e de ensino diferentes, contrários até, entre os dois tipos de ensino, e torna-se mais clara a dificuldade em construir currículos que contemplem idiomas da música popular.

Os problemas decorrentes da integração de vários tipos de música popular na escola, também pela natureza das suas práticas, distinta daquelas utilizadas até então, foram constatados no ensino secundário de música australiano, como descreveram os autores Dunbar-Hall e Wemyss (2000).

A falta de formação e prática dos professores no âmbito dos novos idiomas contemplados foi um desses problemas, apercebendo-se os docentes, rapidamente, de que os métodos utilizados para ensinar música erudita não eram transferiveis por assentarem na leitura de partituras, no conhecimento histórico e em exercícios teóricos de composição harmónica e melódica. Não obstante, a dimensão prática destes tipos de música e o seu carácter repetitivo permitiram a integração de atividades orais e auditivas práticas na aprendizagem de notação musical - o que, normalmente, seria abordado no âmbito da teoria musical - com a adoção de estratégias baseadas em ostinatos rítmicos e melódicos. Este pequeno exemplo vai ao encontro de alguns dos pontos expostos na caracterização das aprendizagens informais propostas por Lucy Green.

Outra ferramenta que surgiu da integração de novas músicas foi a introdução de tecnologias que estão associadas às músicas populares, nomeadamente nos processos de composição musical. A tecnologia associada a estes idiomas pode tornar o ensino de música mais ativo e 
motivador para os alunos e para os professores, na medida em que facilita as relações entre eles, mas também o desenvolvimento e a criação musicais.

Além da introdução de novas abordagens pedagógicas que podem mitigar os desafios associados à inclusão e criatividade, existem outras situações, como a notação musical, que requerem diferentes estratégias, nomeadamente no que concerne à música popular. Nestes idiomas, nem a notação musical nem a sua utilização são universais. Usar novas formas de notação na sala de aula faz com que seja necessário discutir o próprio conceito e considerar que nem todas as músicas podem, ou precisam, ser codificadas da mesma forma que é observável na música erudita. $\mathrm{O}$ facto de muita música não ter o suporte escrito com toda a informação que deve ser tida em conta aumenta o leque de competências musicais que os alunos precisam dominar de forma a darem resposta a constantes e novos desafios.

Apesar dos aspetos descritos serem, na sua génese, uma questão de adaptação dificil resultante de uma mudança súbita de paradigma, a utilização de estilos musicais atuais e mais próximos dos alunos apresenta três desafios constantes (Green, 2006, p. 107): (1) para os alunos com idade escolar, a música popular muda constantemente, semanalmente. Mesmo professores que trabalhem repertório atual terão dificuldades em acompanhar eficazmente "as modas"; (2) muitos estudantes escondem as suas verdadeiras preferências musicais quando estão no contexto escolar, de maneira a simular que o seu gosto se alinha com o dos seus pares, normalmente direcionado para a música dos tops; (3) quando a música popular é introduzida na sala de aula, ela pode deixar de ser considerada pop pelos alunos, reforçando a ideia de que uma simples mudança de repertório que apele aos gostos dos alunos não é suficiente se não surgir aliada a estratégias adequadas ao contexto musical.

Reconhecendo-se a multiplicidade e a variedade de conhecimentos associados à História da Música, Cultura e Humanidade, reconhece-se a necessidade de se fazer escolhas, no contexto escolar, tendendo, dentro do possivel, a valorizar a diversidade cultural. Como relembra Silva (2010), estas escolhas estão na base da construção curricular, nas múltiplas dimensões e nos níveis de decisões curriculares (currículo prescrito e currículo real, nomeadamente).

Valorizando perspetiva crítica e pós-critica do currículo, proposta pelo autor, reconhece-se a impossibilidade de existir justiça curricular, "se o cânon curricular não for modificado para refletir as formas pelas quais a diferença produzia por relações sociais [e culturais] de assimetria" (p. 90). Deste modo, o professor, enquanto um profissional crítico, reflexivo e transformador, deverá ser um agente construtor de currículo, integrando-se numa comunidade educativa, de modo a discutir e pensar seriamente nesta temática a fim de transformarmos o ensino formal de música para que se torne mais aberto, envolvente e ativo. 


\section{CONCLUSÃO}

Existe, de facto, um distanciamento entre a cultura escolar e a cultura de muitos dos seus alunos, e esta realidade é comum tanto no ensino geral como, em particular, no ensino formal de música. Ambas as "escolas" estão presas a modelos característicos de gerações anteriores, desatualizados e dominados por pedagogias heteroestruturantes. Constata-se, portanto, a necessidade de se integrar, com mais evidência, os contributos dos estudos curriculares, no âmbito das teorias pós-criticas, nos dois contextos educativos, reconhecendo-se que todos têm direito ao acesso e ao sucesso no ensino escolar.

Se partimos da ideia de que a cultura é um fator importante, temos de ter em consideração os múltiplos contextos e experiências que os estudantes trazem para a sala de aula. Assim, é necessário que os educadores sejam sensiveis e conhecedores da influência que a cultura tem na vida dos seus estudantes. Um professor culturalmente responsável tem de compreender que os alunos constroem o seu conhecimento de formas variadas e distintas, baseado nos seus backgrounds.

A escola é um espaço-tempo de constante conflito de ideias, significados e valores. No caso da música, é particularmente relevante a dinâmica divergente, e até antagónica, entre a cultura musical da tradição ocidental europeia (a música "clássica" ou erudita) e a música de alguns estudantes (aquela que ouvem). Isto deve-se ao facto da não abertura do currículo, nas instituições de ensino formal de música, a repertórios fora do âmbito deste cânone (McPhail, 2015).

A maior parte dos professores de música concorda que é importante encorajar as crianças e os jovens a experienciarem vários géneros musicais e uma variedade grande de obras, mas insiste em estratégias e repertórios mais tradicionais (Green, 2006; Costa; Pais-Vieira; Pinto, 2017; Hargreaves; Marshal, 2003). A integração de música popular no ensino formal de música pode criar inúmeras oportunidades para tornar as instituições mais inclusivas e menos centradas nos valores e modelos de séculos anteriores. Muito porque a música popular existe como um conjunto de estilos que ligam várias etnias, ideologias, religiões, sexualidades e práticas (DunbarHall; Wemyss, 2000). Este processo, certamente, não será nunca pacífico ou isento de problemas. Cada "música" tem práticas e contextos distintos e, neste caso, contrários em muitos pontos. Isto não significa, contudo, que não haja espaço, em contexto formativo, para mais do que uma, mesmo que a forma de partilha de conhecimento seja dispar.

Não existe uma abordagem pedagógica universal que resulte em todos os contextos culturais e educacionais. Mas uma abordagem informal de ensino e uma aprendizagem musical característica das músicas populares, a par da integração das mesmas, em contextos formais, seriam curricular e pedagogicamente relevantes, não só no reconhecimento das vivências e 
experiências das crianças e dos jovens que não se identificam com a cultura dominante, mas também na transformação daqueles contextos em espaços livres, de participação ativa e crítica.

\section{REFERENCIAS}

APPLE, M.; AASEN, P. The state and the politics of knowledge. New York: Routledge, 2003.

ARCHER, M. Sociology for one world: unity and diversity. International Sociology, v. 6, n. 2, p. 137-147, 1991.

BUTLER, A.; LIND, V.; MCKOY, C. Equity and access in music education: conceptualizing culture as barriers to and supports for music learning. Music Education Research, v. 9, n. 2, p. 241-253, 2007.

COSTA, J.; PINTO, I.; PAIS-VIEIRA, L. A ausência de outras músicas nas aprendizagens em formação musical. Encontro de Investigação em, Música 2017. Braga: Sociedade Portuguesa de Investigação em Música. (aguarda publicação).

DEWEY, J. Democracia e Educação. Lisboa: Didáctica Editora, 2007.

GREEN, L. The effects of the study of popular music on music education. International Journal of Music Education, v. 36, n. 1, p. 23-34, 2000.

HARGREAVES, D.; NORTH, A. The social psychology of music. Oxford: Oxford University Press, 2009.

HARGREAVES, D.; MACDONALD, R.; MIELL, D. What are musical identities, and why are they important? In: HARGREAVES, D.; MACDONALD, R.; MIELL, D. Musical Identities. Oxford : Oxford University Press, 2002. Cap. 2, p. 1-20.

HARGREAVES, D.; MARSHALL, N. Developing Identities in Music Education. Music Education Research, v. 5, n. 3, p. 263-273, 2003.

HEIN, E. Cultural hegemony in music education. The Ethan Hein Blog, 2016. Disponivel em: <http://www.ethanhein.com/wp/2016/final-paperdraft-for-learning-of-culture/>. Acesso em: 2018.

HENLEY, J. A challenge to assumptions of the transformative power of music. 3rd SIMM-posium on the social impact of making music. Porto: [s.n.], 2018.

LEITE, C. O currículo escolar e o exercicio docente face aos desafios da multiculturalidade, em Portugal. V Colóquio Internacional Paulo. Recife: [s.n.], 2005. p. 1-16. 
MCPHAIL, G. J. The right to enhancement: students talking about music knowledge in the secondary curriculum. The Curriculum Journal, v. 25, n. 3, p. 306-325, 2014.

MIDDLETON, R.; MANUEL, P. Popular music. Oxford Music Online, jan. 2001.

MONTEIRO, F. Interpretação e Educação Musical. Revista de la Lista Electrónica Europea de Música en la Educación, v. 8, p. 1-20, 2001. Disponivel em: <http://musica.rediris.es/leeme/revista/monteiro01.pdf>.

MOREIRA, A. Currículo, utopia e pós-modernidade. II Encontro Perspectivas do Ensino de História. São Paulo: Faculdade de Educação de São Paulo. 1996. p. 65-80.

MOREIRA, A. Currículo, cultura e formação de professores. Educar, Curitiba, v. 17, p. 39-59, abr. 2000.

PATACHO, P. Práticas educativas democráticas. Educação \& Sociedade, v. 32, n. 114, p. 39-52, 2011.

ROSA, J. C. Depois de Bomtempo: a Escola de Música do Conservatório Real de Lisboa nos anos de 1842-1862. Revista Portuguesa de Musicologia, v. 10, p. 83-116, 2000. Disponivel em: <http://rpmns.pt/index.php/rpm/article/view/97>.

SHEHAN, P. Transfer of Preference from Taught to Untaught Pieces of NonWestern Music Genres. Journal Of Research In Music Education, v. 33, n. 3, p. 149-158, 1985.

SILVA, T. T. D. Documentos de identidade: uma introdução às teorias do currículo. 3. ed. Belo Horizonte: Antêntica, 2010.

SLOBODA, J.; FORD, B. What Classical Musicians Can Learn from Other Arts about Building Audiences. Understanding Audiences Working Paper 2, p. 2002-2008, 1982. Disponivel em:

<https://www.gsmd.ac.uk/fileadmin/user_upload/files/Research/SlobodaFord_working_paper_2.pdf $>$.

STOER, S. Desocultando o voo das andorinhas: educação inter/multicultural crítica como movimento social. Educação, Sociedade e Culturas, p. 185-211, 2001.

SWANWICK, K. Music, mind, and education. New York: Routledge, 1988.

SWANWICK, K. Music Curriculum Development and the Concept of Features. Journal of Aesthetic Education, v. 23, n. 3, p. 147-162, 1991.

TORRES SANTOMÉ, J. A imperiosa necessidade de uma teoria e prática pedagógica radical crítica: diálogo com Jurjo Torres Santomé. Currículo Sem 
Fronteiras, p. 5-32, 2004. Disponivel em:

<http://www.curriculosemfronteiras.org/vol4iss2articles/jurjo.pdf>.

João Gomes Reis é licenciado em Educação Musical pela Escola Superior de Educação do Politécnico do Porto (ESE-PP) e frequenta atualmente o Mestrado em Ensino de Música Ramo Formação Musical (ESMAE/ESE). Entre outras atividades, foi bolseiro e colabora com o Centro de Investigação em Psicologia da Música e Educação Musical (CIPEM) e com o Núcleo de Apoio à Inclusão Digital (NAID), na ESE, no âmbito do projeto "Apoio a alunos cegos: Musicografia Braille". Participou em conferências e ações de formação no âmbito da divulgação e discussão da temática da musicografia braille.

Pedro Duarte é docente na Escola Superior de Educação do Politécnico do Porto e doutorando na Universidade de Santiago de Compostela, frequentado o Doutoramento em Educação. O autor é mestre em Estudos Especializados em Educação - Administração das Organizações Educativas e mestre em Ensino do 1ㅇe do 2 Ciclos do Ensino Básico. A par da participação em congressos (e encontros similares), tem publicado artigos sobre diferentes temáticas, em revistas e atas de eventos, com especial destaque em áreas como o currículo, supervisão, formação inicial de professores e administração das organizações educativas. 